\title{
RELATIONSHIPS AMONG SPECIFIC GROWTH, SECRETED ACID PHOSPHATASE, INTRACELLULAR AND TOTAL INORGANIC PHOSPHORUS CONCENTRATION IN CHLORELLA FUSCA CULTURED UNDER VARIOUS LEVELS OF NA2HPO4
}

\author{
Ibrahim, H.; El-Shahed, A. and Abd-El-Naeim, M. \\ Botany Department, Faculty of Science, Minia University, Egypt
}

\begin{abstract}
The relationships among specific growth rates, intracellular inorganic phosphate (Pi) and total phosphorus concentrations and specific activities of acid phosphatase (acPase) were studied on the green unicellular alga Chlorella fusca at 1.0, 15.0 and 30.0 $\mu \mathrm{M}$ Na2HPO4. The specific growth, the intracellular $\mathrm{Pi}$ and total phosphorus concentration increased with increasing Na2HPO4 levels. The acid phosphatase activity was inversely correlated with the specific growth rate, the total $\mathrm{P}$ concentrations and the intracellular inorganic concentrations. The P-deficiency induction of acPase activity is related to a decrease in P-availability in Chlorella fusca.
\end{abstract}

Key words: Acid phosphatase - Growth- Phosphorus

\section{Introduction}

Phosphorus is an important structural constituent of many biomolecules such as proteins, phospholipids and nucleic acids; therefore, its regulation is important for plant growth and development (Duff et al., 1994). Phosphorus also required for energy transfer and regulation of metabolism constituting from 0.3 to $0.5 \%$ of plant dry weight (Cashikar et al., 1997). Under conditions of phosphate limitation, the growth and development of plants are particularly dependent upon the availability of phosphates (Dracup et al., 1984).

Among the various dissolved forms of phosphporus, orthophosphates (Pi) is known to be the most biologically available and readily usable form by phytoplankton (Cembella et al., 1984 and Bostrom et al., 1988).

Exposure of algae to phosphorus deficient waters, results in disorders in the metabolism such as decrease in growth, photosynthesis and respiration rate (Davis, 1988; Theodorou et al., 1991 and Garcia-Sanchez et al., 1996).

Phosphatases are a group of enzymes that catalyze the hydrolysis of a large number of phosphomonoesters. It is generally thought that the hydrolysis process that is mediated by phosphatase is related to the availability of $\mathrm{Pi}$. In the blue green alga Anabaena flos-aquae, Healey (1973) reported that the removal of 
Pi from the medium was accompanied by increasing alkaline phosphatase activity. In the flagellate alga Euglena gracilis, the activity of acid phosphatase, also increased under P- deficient conditions (Price, 1962 and Blum, 1965). The induction of phosphatase activity is therefore considered a typical response in algae exposed to P-deficiency.

Orhanovic and Pavella-Vrancic (2000) emphasized that concentration of inorganic phosphorus in culture media controls the biosynthesis of the phosphatases and that the enzyme activity can often be used as an indicator of the Pi requirement in the planktonic community.

Despite the fact that phosphorus is an important and often limiting nutrient there is little knowledge on the nature an regulation of phosphatases in freshwater algae. Alkaline phosphatases were more pronounced than acid phosphatases in the literature cited.

The relationship between the acid phosphatase activity from algal species and the concentration of the available inorganic phosphate has been detected in several reports; Price (1962) and Blum (1965) on the flagellate alga Euglena gracilis. Sommer and Blum (1965); Moller et al., (1975) on microalgae. Weich and Groneli (1989) on Ulva lactuca; Quisel et al., (1996) on Chlamydomonas reinhardtii; Lee (2000 and 2004) on the red macroalga Gracillaria coronopifolia.

The present study deals with determination of the relationship among specific growth rate, intracellular inorganic phosphorus and total phosphorus concentrations as well as the specific activity of extracellular phosphatases isolated from the freshwater green alga Chlorella fusca.

\section{Materials and methods}

\section{1- The tested organism:}

Chlorella fusca was obtained from the culture collection of Gottingen University, Germany. It was maintained in the laboratory on a selective solid medium (Grimme and Boardman, 1972) for subsequent use. All the experiments performed for this alga were done in aerated liquid cultures. Cells were harvested by centrifugation at $3000 \mathrm{rpm}$, the pellets were left to dry on plastic foil and then divided each into two parts; the first one was used for determination of growth parameters and phosphatase activity while the other part was stored in the deep freezer for subsequent isolation and biochemical characterization of phosphatase enzyme.

\section{2- Isolation of fractions enriched in secreted acid phosphatase:}

Freezed tissues were used for preparing fractions of the secreted acid phosphatases. About $0.6 \mathrm{~g}$ fresh weight of the alga were suspended in $5 \mathrm{ml} \mathrm{Chu}$ 10 medium, shaken gently and pelleted by centrifugation at $13,000 \mathrm{~g}$ for $15 \mathrm{~min}$. at $4{ }^{\circ} \mathrm{C}$. The supernatant was collected and the algal pellets were resuspended in the same medium. Washing was repeated five times. The first and the second 
supernatants were pooled and represented the fraction of cell wall-bound acid phospatase. The algal pellet was grown in the growing medium for 4 days at room temperature to obtain the secreted fraction of the enzyme. The secretion of the enzyme was followed according to Pfeiffer (1996).

\section{3- Determination of growth rate of Chlorella fusca:}

A number of criteria namely, fresh weight, content of photosynthetic pigments, cellular soluble and total phosphorus content was estimated in order to determine the specific growth of Chlorella fusca.

Aliquotes of $0.1 \mathrm{gm}$ of Chlorella fusca cells were cultured for 8 days in $250 \mathrm{ml}$ of a mineral medium (Grimme and Boardman 1972). Cultures were aerated and maintained continuously at light intensity of 3000 lux and room temperature $\left(30 \pm 2{ }^{\circ} \mathrm{C}\right)$.

The concentration of $\mathrm{Pi}$ in the medium was adjusted to final concentrations of $1,15,30 \mu \mathrm{M}$ using NaH2PO4. Phosphorus- free medium was also used. Each treatment had three replicates. After 8 days of incubation, cells were collected by centrifugation and the fresh weight was determined as Wo W8 where Wo is the initial weight and W8 is the weight by the end of incubation.

After fresh weight determination, cells of Chlorella were stored at - 85 ${ }^{\circ} \mathrm{C}$ for subsequent determination of photosynthetic pigments, soluble proteins, intracellular phosphorus and total phosphorus as well as the activity of phosphatase enzyme.

\section{3-1 Extraction and estimation of chlorophyll content of Chlorella fusca:}

Previously stored algae were allowed to defrost and $0.025 \mathrm{gm}$ of Chlorella fusca cells of each treatment were crushed thoroughly in sand and excess of acetone $80 \%$ in a mortar. The extract was centrifuged off at 13,000 rpm. The supernatant was adjusted to $10 \mathrm{ml}$ by $80 \%$ acetone. The absorbance of the extract was measured at $645,663 \mathrm{~nm}$ for estimation of chlorophyll a,b and total chlorophyll according to the equation reported by Arnon (1949) as follows:

- Chlorophyll a $(\mathrm{mg} / \mathrm{ml})=12.7$ A $663-2.69$ A 645/ 1000. w.a x v

- Chlorophyll b (mg/ml) = 22.9 A $645-4.68$ A663 / 1000. w.a x v

- Total chlorophyll was derived from the equation:

- Total chlorophyll $=20.2$ A $645+8.02$ A $663 / 1000$. w.a x v

Where:

$\mathrm{A}=$ absorbance at a given wavelength

$\mathrm{a}=$ length of light path in the cell (usually $1 \mathrm{~cm}$ )

$\mathrm{v}=$ volume of the extract in $\mathrm{ml}$

$\mathrm{W}=$ fresh weight of the sample in gm

Carotenoids were estimated according to the equation reported by Metzner et al., (1965) as follows: 
Carotenoids $=4.2$ E $452.5-(0.0264 \mathrm{chl} \mathrm{a}=0.4260 \mathrm{chl} \mathrm{b}) \mathrm{V} / 1000 \mathrm{w}$. Photosynthetic pigments content were also measured for non treated algae as a control.

\section{3-2- Determination of soluble protein concentration in Chlorella fusca:}

Determination was performed according to the method reported by Lowry et al., (1951). For preparation of standard curve for protein determination, an initial concentration of Bovine serum albumin (BSA) was prepared from which a stock working standard $(0.1 \mathrm{mg} / \mathrm{ml})$ was obtained. The working range of concentration was $1-30 \mathrm{mg} / \mathrm{l} .1 \mathrm{ml}$ of Lowry reagent was added to $200 \mu \mathrm{l}$ of each concentration which was incubated at room temperature for exactly $10 \mathrm{~min}$. at the end of which $100 \mu \mathrm{l}$ of folin - cicoalteu reagent was added to each of the reaction mixtures, mixed well and incubated again for $30 \mathrm{~min}$. at room temperature. Blank tubes were prepared to contain $200 \mu \mathrm{l}$ of distilled water and the optical density was measured at $750 \mathrm{~nm}$ against water as a reference. The value of blank was substracted from the value of each concentration and a standard curve was constructed. Samples were treated as standards used for standard curve construction and the optical density was measured at $750 \mathrm{~nm}$, which was plotted on the standard curve to obtain soluble protein concentration.

\section{3-3- Determination of phosphorus in Chlorella fusca cells:}

Soluble and total cellular phosphorus determinations were performed according to Moore \& Chapman (1986) as follows: Stock standard solution (100 $\mathrm{mg} / \mathrm{L})$ and a working standard $(8 \mathrm{mg} / \mathrm{l} \mathrm{P})$ were prepared. Ammonium molybdatesulphuric acid reagent and stannous chloride reagent were prepared. The later was prepared immediately before use by dissolving $0.2 \mathrm{~g}$ of stannous chloride in 100 $\mathrm{ml}$ of $2 \%(\mathrm{v} / \mathrm{v}) \mathrm{HCl}$. The range of concentrations of the working standard was 1.6, 3.2, 4.8, 6.4, 8.0, 9.6 and $11.2 \mu \mathrm{g} / \mathrm{ml}$. To $1 \mathrm{ml}$ of each standard, aliquots of $200 \mu \mathrm{l}$ of ammonium molybdate reagent were added followed by $200 \mu \mathrm{l}$ of stannous chloride reagent and the final volume were adjusted to $5 \mathrm{ml}$ by distilled water. The reaction mixture was incubated at room temperature for $30 \mathrm{~min}$. The optical density was measured at $700 \mathrm{~nm}$ using water as a reference. A calibration curve was constructed for the standards which were used to determine the concentration of the phosphorus in the original sample.

\section{4- Determination of phosphatase activity in Chlorella fusca:}

The activity of acid phosphatase (acPase) was determined according to Pfeiffer (1996) by measuring the release of P-nitrophenol (pNP) from pnitrophenyl phosphate (pNPP). Samples of $200 \mu \mathrm{L}$ cotaining enzyme were incubated with $200 \mu$ Lreaction buffer containing $40 \mathrm{mM}$ Mes/Tris, $\mathrm{pH} 4.5,5 \mathrm{mM}$ pNPP and $10 \mathrm{mM} \mathrm{MgCl} 2.6 \mathrm{H} 2 \mathrm{O}$ for $45 \mathrm{~min}$ at $30^{\circ} \mathrm{C}$. The reaction was stopped and the color was developed by addition of $800 \mu \mathrm{l}$ of $400 \mathrm{mM}$ borate buffer, $\mathrm{pH}$ 9.8. The concentration of pNP was determined using a linear regression of calibration standers. All experiments were performed in ice as triplicates. 


\section{Results}

As the external levels of Na2HPO4 increased, the specific growth increased (Figure 1). It is clear from this figure that all the growth criteria; the fresh weight of the alga, the total chlorophylls, the total carotenoids concentration and total protein concentrations increased by increasing the concentration of the inorganic phosphorus in the medium. Both the intracellular inorganic and the total phosphorus concentrations were also increased with increasing the external Na2HPO4 levels (Figure $2 \mathrm{~A}$ and B).

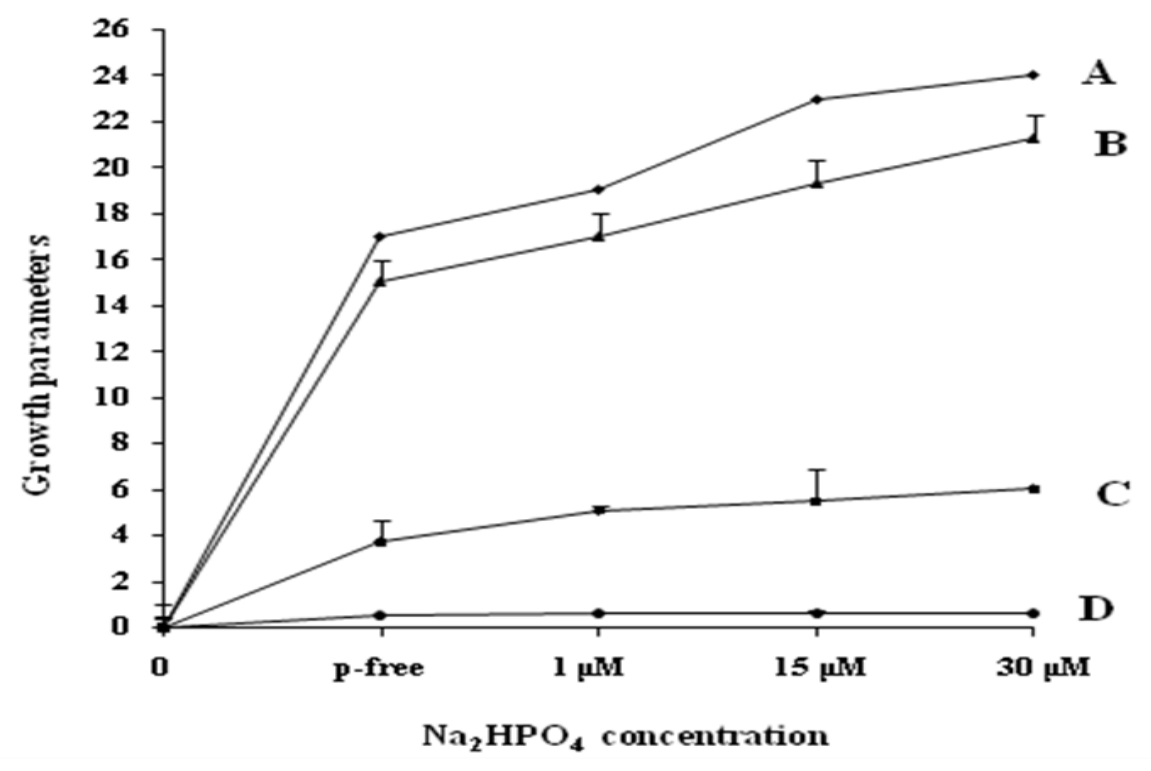

Figure1. Changes in specific growth of Chlorella fusca exposed to various levels of external Na2HPO4. A: Fresh weight of the alga (mg.10-1), B: Total protein concentration (mg / gm f.wt), C: Total chlorophyll concentration (mg / gm f.wt), D: Carotenoid concentration (mg / gm f.wt).

Figure (3) showed that changes in the specific activity of acid phosphatase were inversely related to the concentration of the external inorganic phosphorus. It is clear from this figure that addition of Na2HPO4 at 
Ibrahim, H. et al.
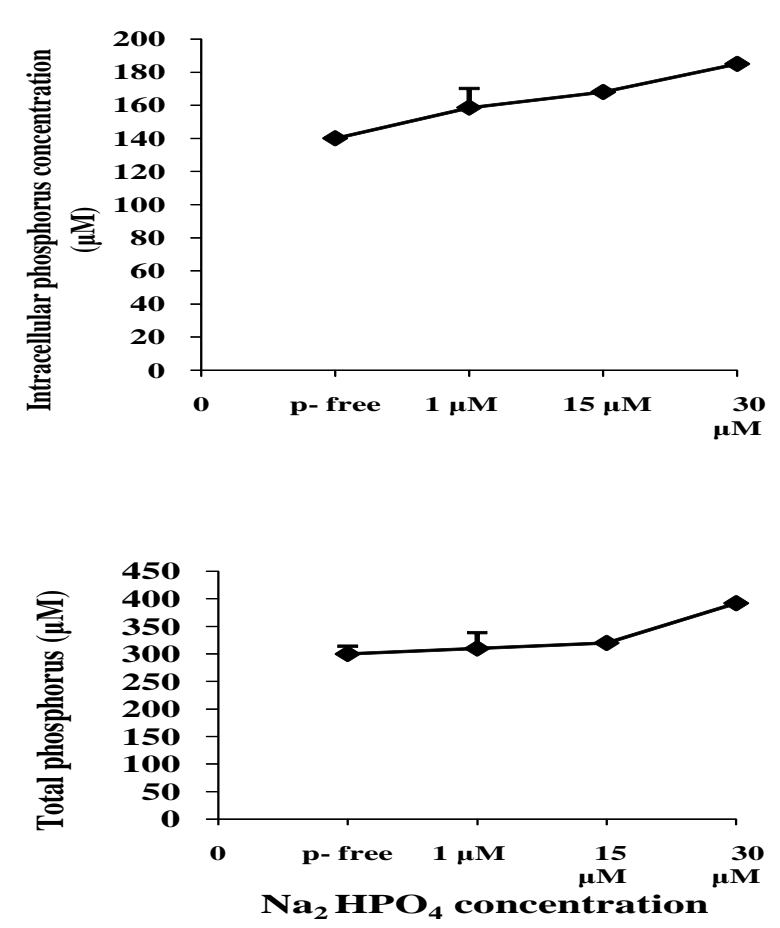

Figure 2. Changes in inorganic and total phosphorus in Chlorella fusca exposed to various levels of external $\left(\mathrm{Na}_{2} \mathrm{HPO}_{4}\right)$.

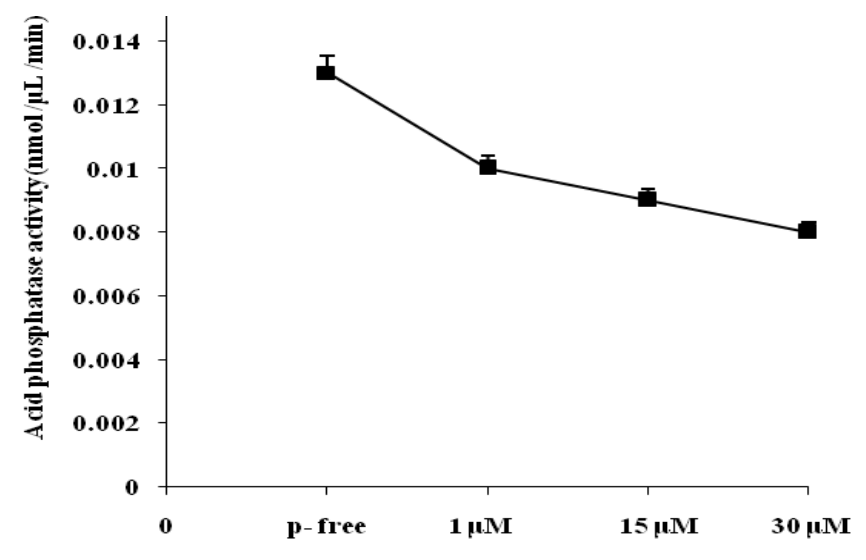

$\mathrm{Na}_{2} \mathrm{HPO}_{4}$ concentration

Figure 3. Relationship between acid phosphatase activity and concentration of inorganic phosphorus in Chlorella fusca. 
concentrations of $1.0,15.0$ and $30.0 \mu \mathrm{M}$ inhibited the initial activity of the enzyme by $23.0 \%, 29.2 \%$ and $38.4 \%$, respectively compared to control.

\section{Dicussion}

The external level of Na2HPO4 affected the total phosphorus and the concentration of intracellular inorganic phosphorus (Pi), the lower the external $\mathrm{Na} 2 \mathrm{HPO} 4$ the lower the intracellular $\mathrm{Pi}$ and total phosphorus concentration (figure 1). It has also been shown in other algae that the levels of intracellular inorganic phosphorus decreased when exposed to P- deficient conditions (BarretLennard et al., 1982; Dracup et al., 1984; Lundberg et al., 1989; Tillberg and Rowley, 1989; Duff et al., 1994; Lee, 2000).

The present results demonstrated a linear correlation between the activity of acid phosphatase, intracellular inorganic phosphorus and total phosphorus concentrations refering to that in Chlorella fusca the acid phosphatase can be used as an indicator of P-deficiency. The increment in acid phosphatase activity in $\mathrm{Pi}-$ limited conditions suggests that the acid phosphatase could be involved in polyphosphate degradation in the tested alga (Chlorella fusca) as has been suggested for some higher plants such as soybeen vegetative storage proteins (Dewald et al., 1992) and some ornamental plants (Duff et al., 1994). Acid phosphatase activity also has been used in higher plants as a biochemical marker of P-limitation (Barret-Lennard et al., 1982) who worked on wheat leaves and Ibrahim (2005) who worked on pollen grains of Zea mays. Increased the activity of acid phosphatase in response to $\mathrm{P}$ - deficient conditions and the secretion of the enzyme have been reported in some crop plants which were studied by Tadano \& Sakai (1991). Similarly, in accordance with data of the present investigation, Gilbert et al. (1999) indicated that P- deficiency in white lupin roots (Lupinus albus) induced a number of coordinated metabolic changes in roots, and possibly in the whole plant.

Similarly to the results obtained by El-Shahed et al. (2006), the in-vitro experiments in this study showed that phosphate ions are potent inhibitors of the activities of the acid phosphatase enzyme in Chlorella fusca (figure 3). A high correlation with intracellular Pi concentration was found for acid phosphatase activity. The induction of acid phosphatase activity is therefore possibly due to a lower intracellular Pi concentration. This study also showed that growth of Chlorella fusca depends on the external supply of Na2HPO4 and that there is a linear relationship between external Na2HPO4 level and the specific growth rates and hence there is a reverse relationship between growth rates and the secretion or even the activity of the enzyme (data not shown) and this observation is in contrast with the conclusion obtained by Ibrahim et al. (2002) who worked on acid phosphatase produced by germinating lily pollen grains. 


\section{References}

Arnon, D. I. (1949). Copper enzymes in isolated chloroplasts. Polyphenoloxidase in Beta vulgaris. Plant Physiol., 24:1-15.

Barret-Lennard, E. G.; Robson, A. D. and Greenway, H. (1982). Effect of phosphorus deficiency and water deficit on phosphatase activities from wheat leaves. J. Exp. Bot., 33:682-693.

Blum, J. J. (1965). Observations on the acid phosphataes of Euglena gracilis. J. Cell Biol., 24:223-234.

Bostrom, B.; Persson, G. and Broberg B. (1988). Bioavialability of different phosphorus forms in freshwater systems. Hydrobiologia, 170:133-155.

Cashikar, A. G.; Kumaresan, R. and Rao, N. M. (1997). Biochemical characterization and subcellular localization of the red kidney been purple acid phosphatase. Plant Physiol., 114:907-915.

Cembella, A. D.; Antla, N. J. and Harrison, P. J. (1984). The utilization of inorganic and organic phosphorus compounds as nutrients by eukaryotic microalgae: A multidisciplinary prespective: Part 1. Crit. Rev. Microbiol., 10:317- 391.

Davis, A. G. (1988). Nutrient interactions in the marine environment. In: Biochemistry of the algae and cyanobacteria (Ed. By D. Rogerse and J. Gallon), Oxford University Press. Proceeding of Phytochem. Soc. Europe, 29:241-256, Oxford, U.K.

Dewald, D. B.; Mason, H. S. and Mullet, J. E. (1992). The soybeen vegetative storage proteins vsp alfa and vsp beta are acid phosphatases active on polyphosphates. J. Biol. Chem., 267:15958-15964.

Dracup, M. N. H.; Barret-Lennard, E. G.; Greenway, H. and Robson, A. D. (1984). Effect of phosphorus deficiency on phosphatase activity of cell walls from roots of subterranean clover. J. Exp. Bot., 35:466-480.

Duff, S. M. G.; Gautam, S. and Plaxton, W. C. (1994). The role of acid phosphatases in plant phosphorus metabolism. Physiologia Plantarum, 90: 791-800.

El-Shahed, A. M.; Ibrahim, H. and Abd-Elnaeim, M. (2006). Isolaton and characterization of phosphatase enzyme from the freshwater macroalga Cladophora glomerata Kutzing (Chlorophyta). Pakistan J. Of Biological Sciences, 9(13):2456-2461.

Garcia-Sanchez, M. J. ; Fernandez, J. A. and Niell, F. X. (1996). Photosynthetic response of P- deficient Gracilaria tenuis tipitata under two different phosphate treatments. Physiologia Plantarum, 96:601-606.

Gilbert, G. A.; Knight, J. D.; Vance, C. P. and Allan, D. L. (1999). Acid phosphatase activity in phosphorus- deficient white lupin roots. Plant Cell Environ., 22:801-810.

Grimme, L. H. and Boardman, N. K. (1972). Photochemical activities of a partical Pi obtained from green algae Chlorella fusca. Biochem. Biophys. Res. Commun, 49:1619-1623. 
Healey, F. P. (1973). Characterization of phosphorus deficiency in Anabaena. J. Phycol., 9: 383-394.

Ibrahim, H.; Perti, H.; Pitterschatscher, K.; Fadl-Allah, E.; El- Shahed, A. Bentrub, F. W. and Obermeyer G. (2002). Release of an acid phosphatase during lily pollen tube growth involves components of secreted pathway. Protoplasma, 219:176-183.

Ibrahim, H. (2005). Biochemical characterization of acid phosphatase from germinating pollen grains of Zea mays. Assuit Univ. J. of Botany, 34 (1): 371- 382.

Lee, T. M. (2000). Phosphate starvation induction of acid phosphatase in Ulva lactuca (Ulvales Chlorophyta). Bot. Bull. Acad. Sinica, 41:19-25.

Lee, T. M. (2004). Induction of acid phosphatase activity by phosphorus deficiency in Gracillaria coronopifolia, Rhodophyta. Phycol., 43:495-500.

Lowry, O. H.; Rosbrough, N. J.; Farr, A. L. and Randall, R. (1951). Protein measurement with the folin phenol reagent. J. Biol. Chem., 193:265-275.

Lundberg, P.; Weich, R. G.; Jensen, P. and Vogel, H. J. (1989). Phosphorus31 and nitrogen-14 NMR studies of the uptake of phosphorus and nitrogen compounds in the marine macroalga Ulva lactuca. Plant Physiol., 89: 1380-1387.

Metzner, H.; Rau, H. and Singer, H. (1965). Untersuchungen zur synchronisierbarkeit einzelner pigmentmangel- Mutantent von Chlorella. Planta, 65:186-194.

Moller, M.; Myklestad, S. and Haug, A. (1975). Alkaline and acid phosphatases of the marine diatoms Chaetoseras affinis var. Willie (Gran.) Hustedt and Skeletonema costatum (Grev.) Clev. J. Exp. Mar. Biol. Ecol., 19:217-226.

Moore, P. D. and Chapman, S. B. (1986). Chemical analysis. In: Methods in plant ecology. Blackwell Sci. Publ., Oxford, Boston, Palo, Alto, Melbourne, 285-344 Pp.

Orhanovic, S. and Pavela-Vrancic, M. (2000). Alkaline phosphatase activity in sea water: Influence of reaction conditions on kinetic parameters of ALP. Croatica Chem.Acta, 73(3):819-830.

Pfeiffer, W. (1996). Auxin induce exocytosis of acid phosphatase in coleoptiles from Zea mays. Physiologia Plantarum, 98: 773-779.

Price, C. A. (1962). Repression of acid phosphatase synthesis in Euglena gracilis. Science, 135:46.

Quisel, J. D.; Wykoff, D. D. and Grossman, A. R. (1996). Biochemical characterization of the extracellular phosphatases produced by phosphorusdeprived Chlamydomonas reinhardtii. Plant Physiol., 111:839-848.

Sommer, J. R. and Blum, J. J. (1965). Cytochemical localization of acid phosphatase in Euglena gracilis. J. Cell Biol., 24:233-251.

Tadano, T. and Sakai, H. (1991). Secretion of acid phosphatases by the roots of several crop species under phosphorus-deficient conditions. Soil Sci. Plant Nutr., 37:120-140. 
Theodorou, M.E.; Elrifi, I. R.; Turpin, D. H. and Plaxton, W. C. (1991). Effects of phosphorus limitation on respiratory metabolism in the green alga Selenastrum minutum. Plant Physiol., 95:1089-1095.

Tillberg, J. E. and Rowley, J. R. (1989). Physiological and structural effects of phosphorus starvation on the unicellular alga Scenedesmus. Physiologia Plantarum, 75:315-332.

Weich, R. G. and Graneli, E. (1989). Extracellular alkaline phosphatase activity in Ulva lactuca L. J. Exper. Marine Biol. Ecol., 129:33-44.

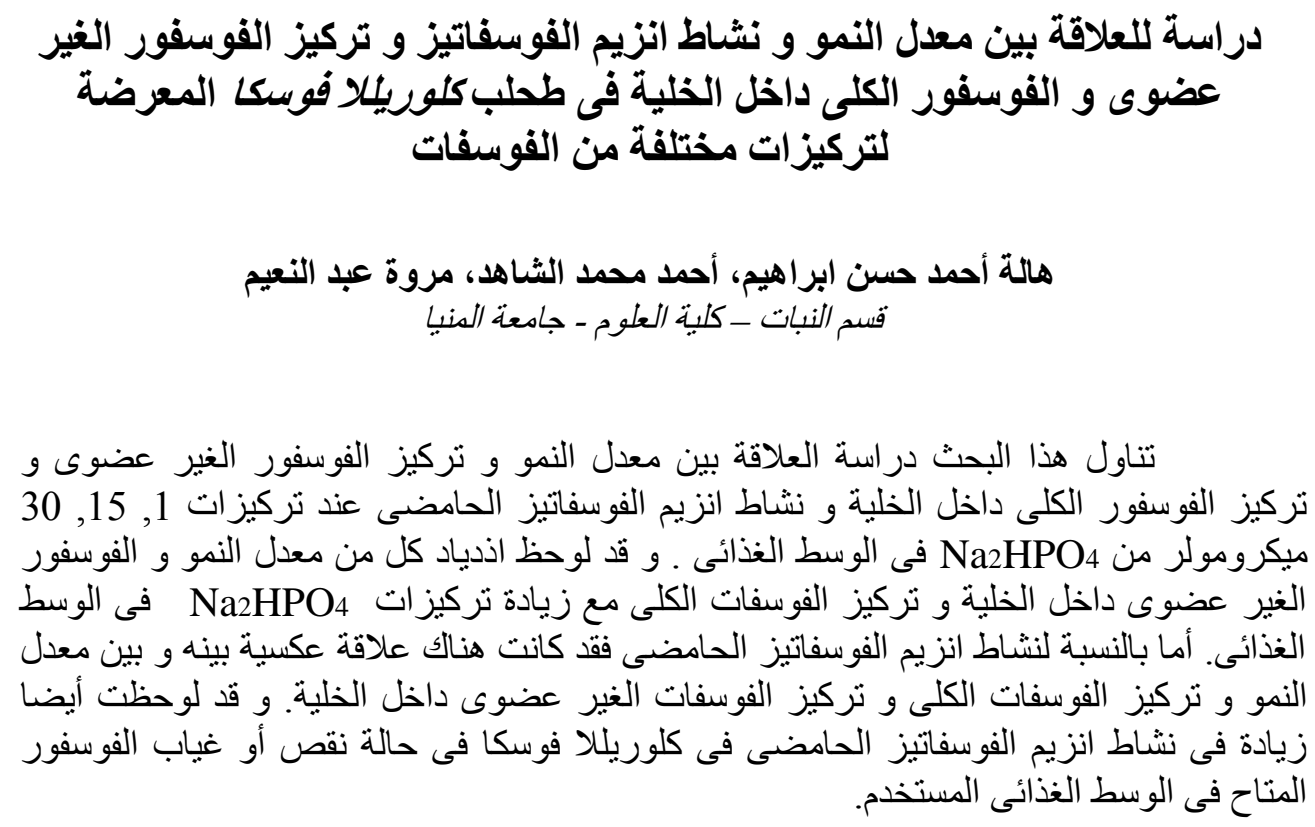

